OPEN ACCESS

Edited by:

Dongsheng Zhou,

Beijing Institute of Microbiology

and Epidemiology, China

Reviewed by:

Pallab Ghosh,

Harvard Medical School,

United States

Fernando Aleman,

Scripps Research Institute,

United States

*Correspondence:

Kai Soo Tan

denkst@nus.edu.sg

Specialty section:

This article was submitted to

Infectious Diseases,

a section of the journal

Frontiers in Microbiology

Received: 08 June 2017 Accepted: 08 September 2017 Published: 26 September 2017

Citation:

Ding Q and Tan KS (2017) Himar1 Transposon for Efficient Random Mutagenesis in Aggregatibacter actinomycetemcomitans. Front. Microbiol. 8:1842. doi: 10.3389/fmicb.2017.01842

\section{Himar1 Transposon for Efficient Random Mutagenesis in Aggregatibacter actinomycetemcomitans}

\author{
Qinfeng Ding and Kai Soo Tan* \\ Faculty of Dentistry, National University of Singapore, Singapore, Singapore
}

Aggregatibacter actinomycetemcomitans is the primary etiological agent of aggressive periodontal disease. Identification of novel virulence factors at the genome-wide level is hindered by lack of efficient genetic tools to perform mutagenesis in this organism. The Himar1 mariner transposon is known to yield a random distribution of insertions in an organism's genome with requirement for only a TA dinucleotide target and is independent of host-specific factors. However, the utility of this system in A. actinomycetemcomitans is unknown. In this study, we found that Himar1 transposon mutagenesis occurs at a high frequency $\left(\times 10^{-4}\right)$, and can be universally applied to wildtype A. actinomycetemcomitans strains of serotypes a, b, and c. The Himar1 transposon inserts were stably inherited in $A$. actinomycetemcomitans transconjugants in the absence of antibiotics. A library of 16,000 mutant colonies of $A$. actinomycetemcomitans was screened for reduced biofilm formation. Mutants with transposon inserts in genes encoding pilus, putative ion transporters, multidrug resistant proteins, transcription regulators and enzymes involved in the synthesis of extracellular polymeric substance, bacterial metabolism and stress response were discovered in this screen. Our results demonstrated the utility of the Himar1 mutagenesis system as a novel genetic tool for functional genomic analysis in $A$. actinomycetemcomitans.

Keywords: mutagenesis, conjugation, biofilm, adherence, DNA transposable elements, periodontal disease

\section{INTRODUCTION}

Aggregatibacter actinomycetemcomitans, a gram-negative coccobacillus is strongly associated with localized aggressive periodontal disease which involves rapid loss of alveolar bone in adolescents (Slots et al., 1980; Zambon, 1985; Haubek et al., 2008). This organism is also implicated in non-oral infections such as endocarditis, septicemia, and osteomyelitis (Martin et al., 1967; Meyer and FivesTaylor, 1998; van Winkelhoff and Slots, 1999). A. actinomycetemcomitans expresses numerous virulence factors including leukotoxin, collagenase, and cytolethal distending toxin which contribute to the destruction of periodontium (Shenker et al., 2004; Kachlany, 2010). Even though substantial progress has been made in understanding the virulence of A. actinomycetemcomitans, it remains a challenge to study the genetics of the organism's colonization and persistence in the oral cavity, and identify novel virulence factors due to limited genetic tools available to manipulate A. actinomycetemcomitans. 
Forward genetics is a powerful tool to identify novel genes critical for virulence. Tn916, Tn5, Tn10, and IS903 based gene delivery systems have been used to generate mutant libraries in $A$. actinomycetemcomitans which led to discovery of genes essential in virulence and survival of $A$. actinomycetemcomitans (Kolodrubetz and Kraig, 1994; Thomson et al., 1999; Kachlany et al., 2000a; Isaza et al., 2008; Nunes et al., 2016). However, these systems suffer from several drawbacks. The Tn916 and Tn5 systems have low efficiency of DNA transposition $\left(\leq 10^{-7}\right)$. Although this can be overcome by the use of Tn10 and IS903 $\$$ kan systems which yield higher transposition efficiency, Tn 10 system has preference for hotspots (Halling and Kleckner, 1982). The cryptic kan gene of the IS903фkan system is expressed only when inserted into an expressed gene in the appropriate reading frame to generate a gene fusion with kan gene (Thomson et al., 1999). Therefore, it remains challenging to obtain genome wide saturated mutagenesis of $A$. actinomycetemcomitans with the currently available mutagenesis systems. Furthermore, efficiency of these genetic manipulation systems varies considerably among serotypes of A. actinomycetemcomitans (Clewell and GawronBurke, 1986; Kolodrubetz and Kraig, 1994).

The mariner family of transposons, first identified in horn fly, is known to be widespread in nature. The Himarl mariner transposon is one of the two known active mariner elements that have been successfully utilized for a number of oral and non-oral bacteria such as Pseudomonas aeruginosa (Withers et al., 2014), Porphyromonas gingivalis (Klein et al., 2012), and oral streptococci (Nilsson et al., 2014). A key feature that separates these elements from many other transposons is their independence from host-specific factors other than the presence of a TA dinucleotide target (Lampe et al., 1998). In addition, the Himarl transposon system is known to yield a random distribution of insertions in genome (Nilsson et al., 2014; Withers et al., 2014). However, the usefulness of this mutagenesis system in $A$. actinomycetemcomitans has not been determined. In this study, we report the utility of the Himar1 transposon system to perform genome wide mutagenesis in A. actinomycetemcomitans of different serotypes. Since biofilm formation is critical for A. actinomycetemcomitans' persistence in the oral cavity, in this work, we describe the genetic screen and present data that supports its use as an effective method for identifying novel genetic elements involved in the biofilm formation of A. actinomycetemcomitans.

\section{MATERIALS AND METHODS}

\section{Bacterial Strains and Culture Conditions}

Aggregatibacter actinomycetemcomitans ATCC 700685 (strain HK1651, serotype b), ATCC 33384 (strain NCTC 9710, serotype c), ATCC 43717 (strain SUNYab 75, serotype a), ATCC 43719 (strain SUNYab 67, serotype c) were obtained from the American Type Culture Collection (Manassas). All A. actinomycetemcomitans strains used in this study were chloramphenicol and kanamycin sensitive. Bacteria were cultured in brain heart infusion (BHI) broth (Acumedia) and incubated at $37^{\circ} \mathrm{C}$ in an atmosphere supplemented with $5 \% \mathrm{CO}_{2}$.
E. coli 1354 (Barrett et al., 2008), a diaminopimelic acid (DAP) auxotroph, was cultured in LB broth (Acumedia) supplemented with $100 \mu \mathrm{g} / \mathrm{mL}$ DAP (Sigma) and incubated with aeration at $37^{\circ} \mathrm{C}$.

\section{Transposon Mutagenesis}

The Himar1 transposon delivery plasmid, pUTE664-oriT (Figure 1), was kindly provided by $\mathrm{Mr}$. Yahua Chen from the National University of Singapore. pUTE664-oriT was transformed into E. coli 1354 by electroporation, and selected on LB agar supplemented with $100 \mu \mathrm{g} / \mathrm{mL}$ DAP (Sigma) and $20 \mu \mathrm{g} / \mathrm{mL}$ chloramphenicol. A library of A. actinomycetemcomitans transconjugants was generated as follows. Overnight cultures of A. actinomycetemcomitans and E. coli 1354pUTE664-oriT were diluted 1:10 in fresh BHI and LB broth supplemented with $100 \mu \mathrm{g} / \mathrm{mL}$ DAP and $20 \mu \mathrm{g} / \mathrm{mL}$ chloramphenicol, respectively, and grown for $6 \mathrm{~h}$. Conjugation was performed by mixing $A$. actinomycetemcomitans $\left(5 \times 10^{8}\right.$ $\mathrm{CFU})$ and $E$. coli 1354pUTE664-oriT $\left(1 \times 10^{8} \mathrm{CFU}\right)$ and resuspending in a final volume of $50 \mu \mathrm{L}$ fresh BHI broth with DAP $(100 \mu \mathrm{g} / \mathrm{mL})$, and spreading onto a piece of cellulose nitrate paper (Sartorius) placed over the surface of a BHI agar plate. Conjugation was allowed to take place for $6 \mathrm{~h}$ at $37^{\circ} \mathrm{C}$ in an aerobic atmosphere with $5 \% \mathrm{CO}_{2}$. Bacteria were washed off from the surface of the filter paper with $1 \mathrm{~mL}$ BHI broth, and $100 \mu \mathrm{L}$ of the bacterial suspension was plated on BHI selective

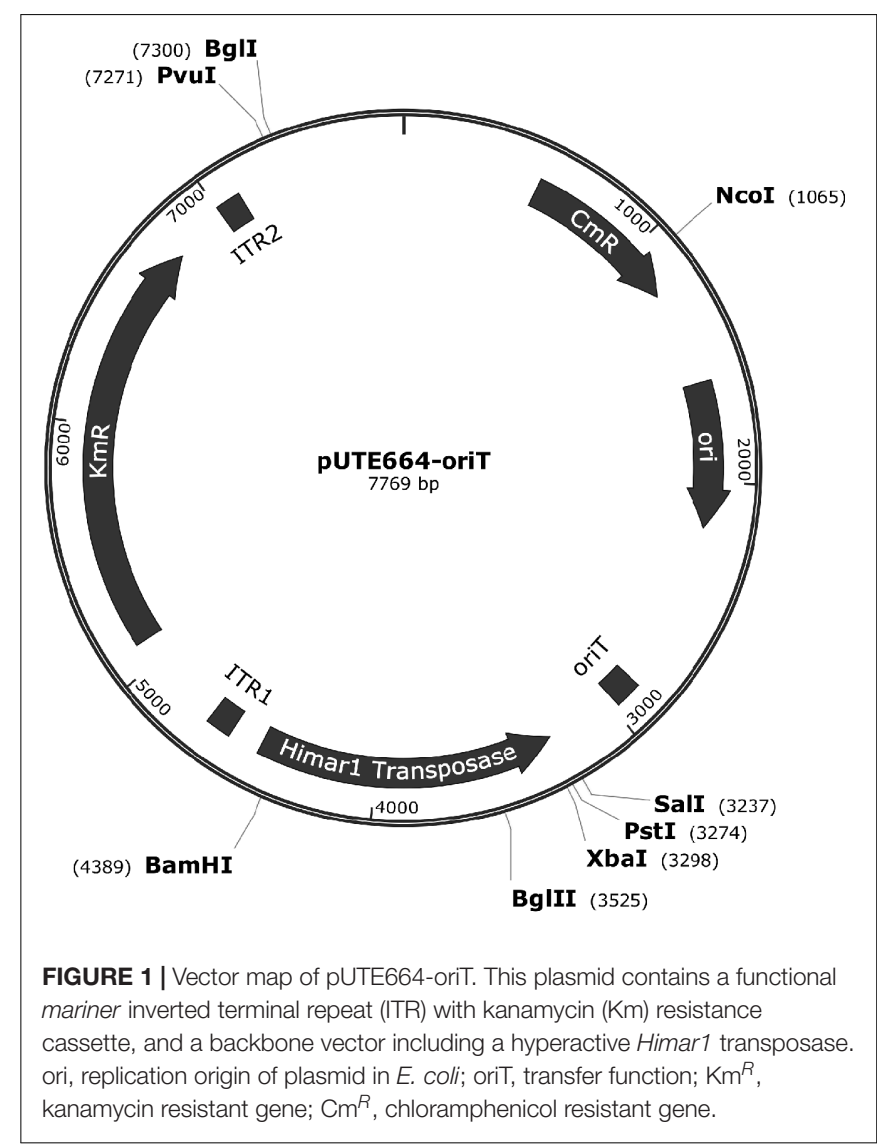


agar supplemented with $12.5 \mu \mathrm{g} / \mathrm{mL}$ kanamycin, and incubated at $37^{\circ} \mathrm{C}$ in an atmosphere with $5 \% \mathrm{CO}_{2}$ for $48 \mathrm{~h}$. The frequency of transposition was calculated as the number of mutants on selective agars (plasmid recipient) divided by the number of E. coli 1354pUTE664-oriT (plasmid donor).

\section{Characterization of A. actinomycetemcomitans Transposon Mutants}

To determine if the Himar1-based transposon has integrated into the genome of $A$. actinomycetemcomitans, each isolated single colony of transposon mutants was picked and inoculated on BHI agar supplemented with either $12.5 \mu \mathrm{g} / \mathrm{mL}$ kanamycin or $20 \mu \mathrm{g} / \mathrm{mL}$ chloramphenicol in parallel. Following successful integration of transposon into the bacterial genome, the backbone of plasmid conferring resistance to chloramphenicol resistant gene will be lost. Therefore, being resistant to kanamycin and sensitive to chloramphenicol is an indication that the plasmid has integrated into the genome. The stability of the transposon inserts was determined through serial passaging of isolated mutants on BHI agar without antibiotics for seven passages. The presence of the Himarl transposon cassette in the genome of these mutants was further validated by PCR. Genomic DNA was isolated from these mutants using the QIAamp DNA mini purification kit (Qiagen) according to the manufacturer's protocol. PCR reaction consisted of $100 \mathrm{ng}$ of genomic DNA, $0.5 \mu \mathrm{M}$ each of forward and reverse primers targeting the kanamycin cassette, GoTaq Master Mix in a final volume of $20 \mu \mathrm{L}$. Sequences of primer used were HimarKm forward (5'-CCGGTATAAAGGGACCACCT) and reverse $\left(5^{\prime}\right.$ - CAGGCTTGATCCCCAGTAAG). The PCR thermocycling consisted of an initial denaturation at $94^{\circ} \mathrm{C}$ for $3 \mathrm{~min}$ followed by 35 cycles of $94^{\circ} \mathrm{C}$ for $40 \mathrm{~s}, 59^{\circ} \mathrm{C}$ for $40 \mathrm{~s}$, and $72^{\circ} \mathrm{C}$ for $30 \mathrm{~s}$, and a final extension of $72^{\circ} \mathrm{C}$ for $10 \mathrm{~min}$. The PCR products were analyzed on a $1.5 \%$ agarose gel.

\section{Southern Blot Analysis}

Genomic DNA was digested with the restriction enzymes EcoRI (Promega) and BamHI (Promega). Following digestion, DNA fragments were purified by ethanol precipitation. Purified DNA fragments were electrophoresed on a $0.8 \%$ agarose gel (BioRad). DNA was transferred to a nitrocellulose membrane (BioRad) via capillary transfer for Southern hybridization which was carried out as described previously (Sambrook et al., 1989). A $600 \mathrm{bp}$ fragment of the Himar1 transposon was amplified by PCR as described above using primers HimarKm forward and reverse. This DNA fragment was used as probe. Labeling and detection of the probe was carried out using the DIG high prime DNA labeling and detection kit (Roche) according to the manufacturer's protocol.

\section{Identification of Transposon Insertion Site}

To determine the site of Himarl insertion, genomic DNA was isolated from the mutants using the QIAamp DNA mini purification kit (Qiagen) according to the manufacturer's protocol. DNA sequences flanking the transposon were determined by inverse PCR and DNA sequencing. Bacterial genomic DNA was digested with Sau3AI (Promega) and self-ligated with T4 DNA ligase (Promega), and used as template for PCR. Inverse PCR was carried out using primers $\mathrm{H} 2$ (5'- CCAACCTTCAAATGATTCCC) and $\mathrm{H} 3$ (5' - GGTACTATATAAAAATAATATGCATTTAATACTAGCG), which hybridize to the end of the kanamycin resistance gene and are oriented outward. PCR reaction consisted of $2 \mu \mathrm{L}$ of ligation mix, $0.5 \mu \mathrm{M}$ each of $\mathrm{H} 2$ and $\mathrm{H} 3$ primers, GoTaq Master Mix (Promega), in a final volume of $50 \mu \mathrm{L}$. The thermal cycling protocol used was an initial denaturation of $94^{\circ} \mathrm{C}, 3 \mathrm{~min}$ for 1 cycle, followed by 35 cycles of $94^{\circ} \mathrm{C}$ for $30 \mathrm{~s} ; 57^{\circ} \mathrm{C}$ for $30 \mathrm{~s}$ and $72^{\circ} \mathrm{C}$ for $2 \mathrm{~min}$. The PCR product was purified using a PCR purification kit (Promega) and sequenced using primer H4 (5'-TATGCATTTAATACTAGCGACG). DNA sequences obtained were analyzed by BLASTN to determine the location of transposon insertion sites.

\section{Screening for Mutants Defective in Biofilm Formation}

A library of A. actinomycetemcomitans ATCC 700685 transposon mutants were generated as described above. A. actinomycetemcomitans biofilms were cultured in 96-well flat bottom polystyrene plates (Thermo Fisher Scientific) and incubated at $37^{\circ} \mathrm{C}$ supplemented with $5 \% \mathrm{CO}_{2}$ for $24 \mathrm{~h}$. Crystal violet assay was carried out to quantify the amount of biofilm formed. Planktonic cells were removed and the biofilm was washed once with sterile PBS to remove residual planktonic cells. The biofilm was fixed with methanol for $10 \mathrm{~min}$, after which methanol was removed and the wells allowed to air dry. Subsequently, biofilm was stained with $1 \%$ crystal violet (Sigma) for $10 \mathrm{~min}$, and excess dye was removed by washing the well with distilled $\mathrm{H}_{2} \mathrm{O}$. Bound crystal violet was dissolved using $33 \%$ acetic acid (Sigma), and absorbance read at optical density $580 \mathrm{~nm}$. Presumptive biofilm deficient mutants obtained from the initial screen were retested in three independent trials. Each putative biofilm deficient mutant was inoculated into BHI broth and the optical density at $600 \mathrm{~nm}$ was determined following $24 \mathrm{~h}$ incubation at $37^{\circ} \mathrm{C}$ in an atmosphere with $5 \% \mathrm{CO}_{2}$. Transposon insertion sites were determined only for selected mutants which were not defective in growth but deficient in biofilm formation compared to the wild-type strain.

\section{RESULTS}

\section{Himar1 Transposon Mutagenesis in A. actinomycetemcomitans}

We found that Himar1-based transposon mutagenesis can be successfully applied in four different $A$. actinomycetemcomitans strains, belonging to serotypes a, b, and c. The transposition frequencies for all the four bacterial strains did not vary significantly at $\times 10^{-4}$, indicating that high frequency of transposition was obtained. For each strain, randomly picked transconjugants $(n=31)$ were kanamycin resistant and 
chloramphenicol sensitive, demonstrating that the plasmid containing the mariner transposon was not capable of replicating in A. actinomycetemcomitans (Figure 2). The stability of transposon inserts was determined in A. actinomycetemcomitans ATCC 700685 (serotype b) which is the most commonly isolated serotype from patients with aggressive periodontitis (Zambon et al., 1983). The presence of the transposon inserts was determined in 31 randomly picked transconjugants by determining their ability to grow on kanamycin resistant agar after seven passages. At the 7 th passage, bacterial cells would have undergone at least 150 generations since the doubling time of
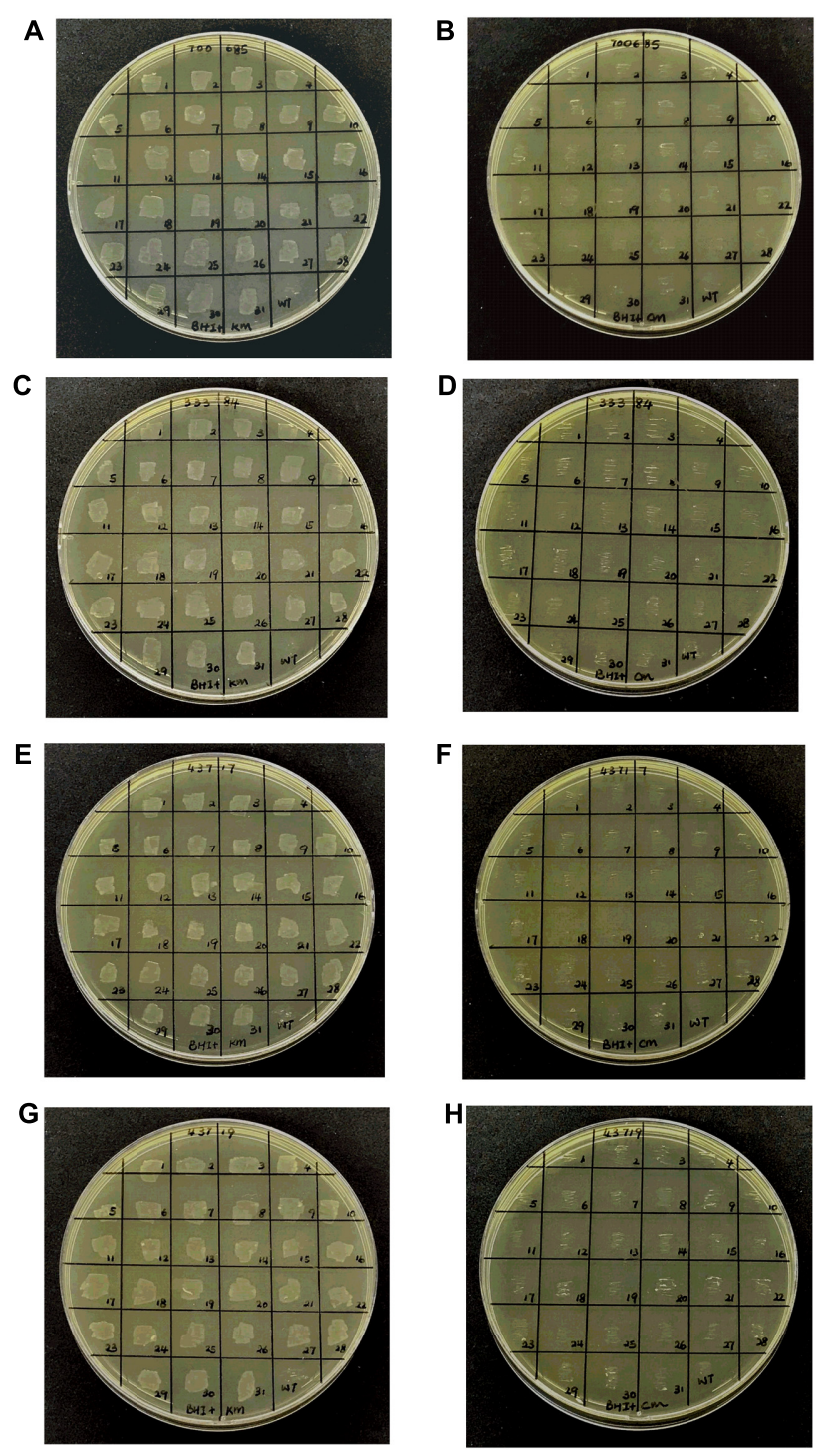

FIGURE 2 | Resistance of Aggregatibacter actinomycetemcomitans transconjugants. Random transconjugants $(n=31)$ were selected and inoculated on either $\mathrm{BHI}$ agar supplemented with kanamycin $(\mathbf{A}, \mathbf{C}, \mathbf{E}, \mathbf{G})$ or chloramphenicol $\mathbf{( B , D , F , H ) . ~ T h e ~ r e s i s t a n c e ~ o f ~} A$. actinomycetemcomitans ATCC 700685 (A,B), 33384 (C,D), 43717 (E,F), and 43719 (G,H) wild-type (indicated as WT), and transconjugants to kanamycin and chloramphenicol are shown.
A. actinomycetemcomitans is about $3 \mathrm{~h}$ (Ding et al., 2016). This is consistent with previous reports that transposon insertions are stably inherited in A. actinomycetemcomitans (Kolodrubetz and Kraig, 1994; Thomson et al., 1999). We found that all 31 transconjugants were able to grow on agar plates with kanamycin following serial passaging (data not shown). PCR further showed the presence of the transposon cassette in the genome of these mutants (Figure 3). Mutants were randomly picked and Southern blot analysis was performed to confirm single transposon insertion. All 13 mutants analyzed showed single insertion in the genome (Figure 4).

\section{Isolation of $A$. actinomycetemcomitans Mutants with Deficiency in Biofilm Formation}

Biofilm formation is one of the important mechanisms employed by $A$. actinomycetemcomitans to enhance their survival in the oral cavity. We employed the Himar1 transposon insertion library to identify mutants defective in biofilm formation in A. actinomycetemcomitans ATCC 700685. Approximately 16,000 transposon mutants were obtained from our library of mutants, which have been verified beforehand to be kanamycin resistant and chloramphenicol sensitive. These mutants were screened for defects in biofilm formation using a microtiter plate biofilm assay. About $40 \%$ of these mutants were found to be defective in growth. As a mutation conferring a growth defect would affect biofilm formation directly or indirectly, only mutants exhibiting growth similar to that of wild-type strain were further studied (Figures 5A,B). A total of 25 mutants were identified to be biofilm deficient with biofilm biomass significantly lower than wild-type strain. The location of the transposon insertion sites in these mutants were determined and are shown in Table 1. Among the 22 mutants with transposon insertions in genes with annotated functions, eight belonged to putative membrane proteins including ion transporters, efflux pumps and secretion systems. The other 10 biofilm

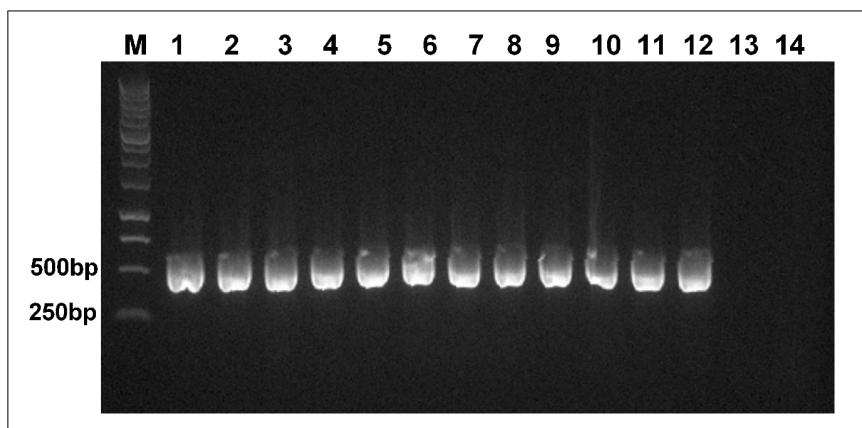

FIGURE 3 | Verification of the presence of Himar1 transposon cassette. Genomic DNA was extracted from 11 randomly picked

A. actinomycetemcomitans transconjugants after seven serial passages. PCR was carried out using primers targeting the kanamycin resistance cassette. Lane M: 1 kb ladder (Promega); lane 1-11: randomly picked mutants with Himar1 transposon insertions; lane 12: pUTE664-oriT (positive control); lane 13: genomic DNA of $A$. actinomycetemcomitans ATCC 700685; lane 14: no template DNA (negative control). 


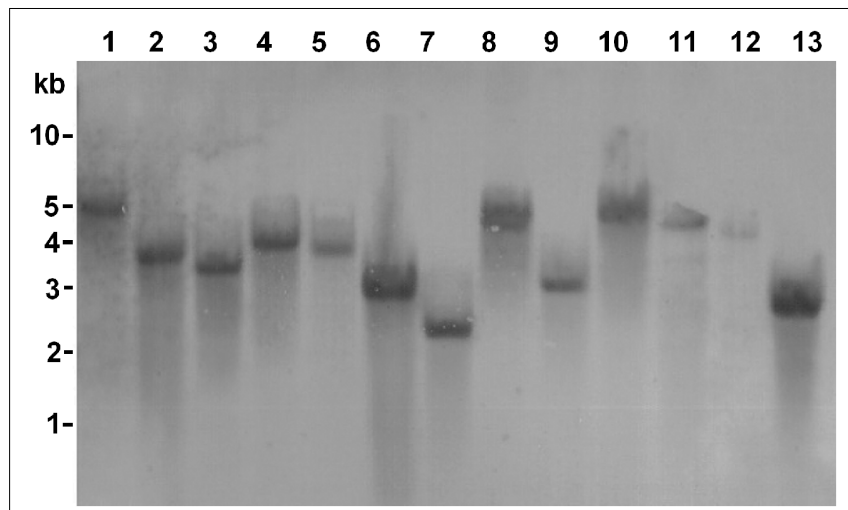

FIGURE 4 | Southern blot of Himar1 transposon insertions. Genomic DNAs were extracted from 13 random transconjugants. DNA was digested with EcoRI and BamHI. Digoxigenin-labeled DNA containing the insertion sequence was used as a probe. The sizes of DNA markers are shown on the left in kilobases. Lanes 1-13 consisted of digested DNA from random transconjugants.

defective mutants possessed disruption in genes encoding putative enzymes involved in the synthesis of extracellular polymeric substance (EPS), proteins involved in bacterial metabolism and oxidative stress response, while three mutants with disruptions in transcription regulators were identified (i.e., transcriptional regulator TyrR, and transcriptional regulator LysR) to be important for biofilm formation. A mutant with transposon insertion in the pilus gene $f l p-1$ which has been previously reported to be essentially in adherence of A. actinomycetemcomitans was also identified in our screen.

\section{DISCUSSION}

We have demonstrated the use of Himarl-based transposon for random mutagenesis in A. actinomycetemcomitans. The transposition frequency was high at $\times 10^{-4}$ for all four strains of $A$. actinomycetemcomitans belonging to serotypes a, $\mathrm{b}$, and $\mathrm{c}$. This transposition efficiency was higher than the reported transposition frequency of Tn916 and Tn5 which is $\times 10^{-7}$ (Clewell and Gawron-Burke, 1986), and similar to the efficiency of Tn10 and IS903фkan systems. However, the Tn10 system has preference for hotspots containing six base pair symmetrical consensus sequence of 5'-GCTNAGC-3', while the IS903 system requires host factors such as GTP for transposition (Coros et al., 2005). Himar1 transposon only requires TA dinucleotides for successful insertion. This is in contrast to other transposon systems such as $\operatorname{Tn} 916$ and $\operatorname{Tn} 5$, which require longer and more complex consensus motifs for insertion (Goryshin et al., 1998; Mullany et al., 2012). Analysis of the genome sequence of $A$. actinomycetemcomitans revealed that the $2.1 \mathrm{Mb}$ DNA contains $1.2 \times 10^{5} \mathrm{TA}$ sites which could have accounted for the high frequency of transposition obtained in this study. The transposition of Himar1 in A. actinomycetemcomitans genome was stable since
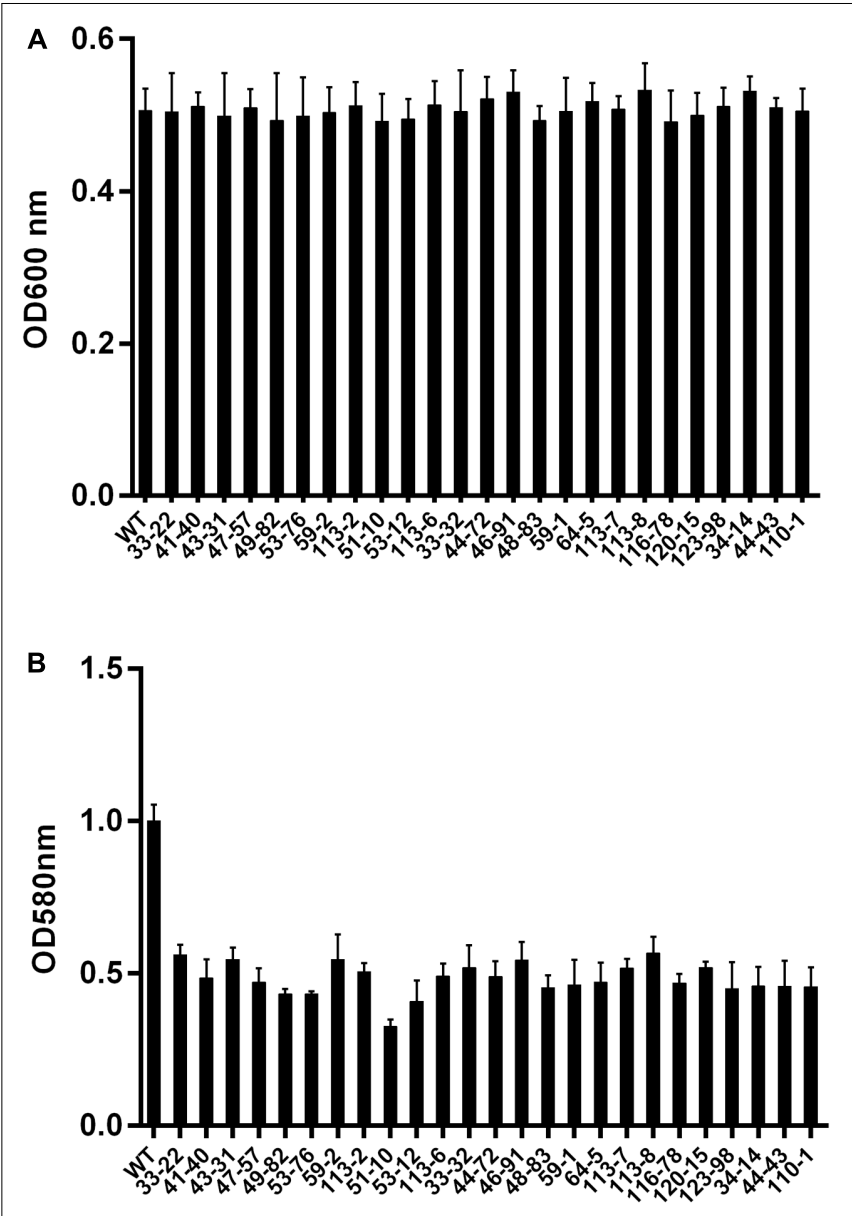

FIGURE 5 | The biofilm forming ability of $A$. actinomycetemcomitans transconjugants. (A) Culture density of biofilm deficient mutants following overnight incubation at $37^{\circ} \mathrm{C}$ in an atmosphere with $5 \% \mathrm{CO}_{2}$. (B) Fold differences in biomass in biofilm deficient transconjugants. Mutants were picked and cultured in 96-well polystyrene plates for $24 \mathrm{~h}$, and the biomass of mutants were determined by crystal violet assay. WT: wild-type strain A. actinomycetemcomitans 700685 .

all the mutants remained kanamycin resistant after at least 150 generations when serially passaged in the absence of antibiotic selection.

Even though substantial progress has been made in understanding the virulence of A. actinomycetemcomitans, it remains a challenge to study the genetics of the organism's colonization and persistence in the oral cavity, and identify novel virulence factors due to limited genetic tools available to manipulate A. actinomycetemcomitans. So far, the recipient strains of $A$. actinomycetemcomitans used in transposon mutagenesis studies are limited to nalidixic acid or rifampin resistant isolates of A. actinomycetemcomitans (Kolodrubetz and Kraig, 1994; Thomson et al., 1999; Kachlany et al., 2000a; Isaza et al., 2008; Nunes et al., 2016). These strains are employed as these antibiotics are used for counter-selection during conjugation experiments with E. coli. In this work, we employed an E. coli DAP 
TABLE 1 | Transposon insertion sites in Aggregatibacter actinomycetemcomitans ATCC 700685 mutants with reduction in biomass.

\begin{tabular}{|c|c|c|c|c|c|}
\hline Functional groups & Mutant No. & Gene locus* & Putative function & Reduction in biomass & Previously described \\
\hline \multirow[t]{8}{*}{ Membrane proteins } & $33-22$ & CF65_00062 & multidrug resistance protein & $43.9 \%$ & No \\
\hline & $41-40$ & CF65_02975 & integral membrane protein & $51.5 \%$ & No \\
\hline & $43-31$ & CF65_02334 & outer membrane protein $\mathrm{P} 1$ precursor & $45.5 \%$ & No \\
\hline & $47-57$ & CF65_01344 & magnesium transporter CorA & $53.0 \%$ & No \\
\hline & $49-82$ & CF65_01341 & multidrug efflux protein & $56.8 \%$ & No \\
\hline & $59-2$ & CF65_02805 & peptidase C39 & $56.8 \%$ & No \\
\hline & $53-76$ & CF65_02294 & $\mathrm{Na}^{+} / \mathrm{H}^{+}$anti-porter $\mathrm{NhaC}$ & $45.5 \%$ & No \\
\hline & $113-2$ & CF65_02532 & TonB-dependent receptor & $49.4 \%$ & No \\
\hline \multirow[t]{3}{*}{ Gene regulation } & $51-10$ & CF65_01698 & transcriptional regulator & $67.5 \%$ & No \\
\hline & $53-12$ & CF65_01579 & transcriptional regulator, TyrR & $59.2 \%$ & No \\
\hline & $113-6$ & CF65_01794 & transcriptional regulator, LysR family & $51.0 \%$ & No \\
\hline \multirow[t]{10}{*}{ Metabolism } & 33-32 & CF65_02251 & biotin sulfoxide reductase & $48.2 \%$ & No \\
\hline & $44-72$ & CF65_02933 & sulfur acceptor protein CsdL & $51.0 \%$ & No \\
\hline & $46-91$ & CF65_02631 & UDP-phosphate galactose phosphotransferase & $45.7 \%$ & No \\
\hline & $48-83$ & CF65_01934 & histidine phosphatase & $54.7 \%$ & No \\
\hline & $59-1$ & CF65_02382 & glucuronate isomerase & $53.9 \%$ & No \\
\hline & $64-5$ & CF65_02983 & pyruvate formate-lyase & $52.9 \%$ & No \\
\hline & $113-7$ & CF65_03351 & tRNA-Lys & $48.3 \%$ & No \\
\hline & $113-8$ & CF65_02683 & electron transporter & $43.3 \%$ & No \\
\hline & $116-78$ & CF65_03076 & 23 S ribosomal RNA & $53.2 \%$ & No \\
\hline & $120-15$ & CF65_00557 & ATPase & $48.1 \%$ & No \\
\hline \multirow[t]{4}{*}{ Other functions } & $123-98$ & CF65_00867 & Flp-1 & $55.1 \%$ & Yes \\
\hline & $34-14$ & CF65_02545 & hypothetical protein & $54.2 \%$ & No \\
\hline & $44-43$ & CF65_00379 & hypothetical protein & $54.3 \%$ & No \\
\hline & $110-1$ & CF65_01357 & hypothetical protein & $54.5 \%$ & No \\
\hline
\end{tabular}

* Obtained from NCBI.

auxotroph as the donor so that counter-selection during conjugation is independent of antibiotic selection. Using this approach, we showed that Himarl transposon mutagenesis can be achieved in four different wild-type strains of A. actinomycetemcomitans encompassing serotypes a, b, and $c$ which are the predominant oral isolates (Dahlén et al., 2002; Yang et al., 2005; Teixeira et al., 2006) with no resistance gene markers.

Biofilm formation is an important virulence attribute of A. actinomycetemcomitans. Bacteria in biofilm exhibit an increased resistance to antibiotics and killing by host defenses compared to their planktonic counterparts (Thrower et al., 1997; Fine et al., 2001). Despite the importance of biofilm formation in the pathogenesis of A. actinomycetemcomitans, our understanding of key genes involved in the establishment of a structured bacterial community formation is still limited. Through screening of a mutant library of 16,000 transconjugants, 25 mutants were identified to be defective in biofilm formation without significant impairment in growth compared to the wild-type. We have identified one mutant with insertion in genes previously known to be associated with $A$. actinomycetemcomitans biofilm formation, and 21 mutants with insertions in genes which have not been reported to be involved in biofilm in A. actinomycetemcomitans but reported elsewhere to be critical in biofilm formation in other bacterial species. The genes identified in our screen include membrane proteins, structural proteins and metabolic enzymes.

The tight adherence (tad) locus comprises 14 genes $(f l p-1, f l p-2, \operatorname{tad} V, \quad r c p C A B$, and tadZABCDEFG) encoding factors that are essential for biofilm formation, colonization and pathogenesis in A. actinomycetemcomitans. Mutations in this gene locus cause loss of adherence, co-aggregation and formation of biofilm in A. actinomycetemcomitans (Kachlany et al., 2000b; Planet et al., 2003; Perez et al., 2006). $f l p-1$ is the gene encoding the major structural component of Flp pilus (Inoue et al., 1998). In our screen, mutation of $f l p-1$ resulted in significant reduction in biofilm formation in A. actinomycetemcomitans which is in consistent with the previous findings that $f l p-1$ plays a key role in the pathogenesis of $A$. actinomycetemcomitans.

Our screen uncovered a mutant with disruption in putative iron transporters namely TonB-dependent receptor. We speculate that this gene is likely critical to facilitate the import of iron from the extracellular environment into the periplasmic space in A. actinomycetemcomitans. Levels of iron in the environment have been reported to regulate biofilm formation of A. actinomycetemcomitans. Under iron chelated conditions, fewer and larger aggregates form with poorly attached, weaker biofilms, compared to biofilms cultured in presence of iron (Rhodes et al., 2007; Amarasinghe et al., 2012). Several other membrane protein mutants were also discovered to be deficient in biofilm formation. These include a putative magnesium 
transporter and efflux pumps. Electrostatic interactions contribute to biofilm cohesion and cations such as magnesium are significant cross linkers of the biofilm matrix because they contribute to the integrity and stability of the outer membranes of the bacteria (Geesey et al., 2000). While the role of efflux pumps in biofilm formation in A. actinomycetemcomitans has not been established, efflux pumps have been shown to be important in the development of biofilm in $P$. aeruginosa (De Kievit et al., 2001) and E. coli (Kvist et al., 2008). In our screen, we identified two putative multidrug resistance proteins and a sodium-hydrogen antiporter to be important in biofilm. These proteins could support biofilm formation through clearing metabolic waste products and regulating intracellular $\mathrm{pH}$, respectively. A transposon mutant of A. actinomycetemcomitans with insertional mutation in C39 peptidase was found to have reduced biofilm formation. This putative protein of the type I secretion family could be involved in the secretion of proteins essential in biofilm development.

Putative genes encoding several enzymes either directly involved in biofilm structure or metabolic processes were found to be involved in biofilm formation. The putative UDP-phosphate galactose phosphotransferase gene of A. actinomycetemcomitans could be functioning through affecting the production of EPS (Levander and Rådström, 2001; Dertli et al., 2013). EPS are biopolymers of microbial origin in which biofilm microorganisms are embedded. EPS determines the immediate conditions of life of biofilm cells living in this microenvironment by affecting adherence and mechanical stability (Flemming et al., 2007). The activity of pyruvate formate-lyase, an enzyme involved in synthesis of formate is increased in Staphylococcus aureus biofilm, while formate significantly increased Campylobacter jejuni's biofilm formation under low oxygen tension (Leibig et al., 2011). Thus, formate might play a role in optimizing A. actinomycetemcomitans's adaptation from planktonic form to biofilm. In our screen, a mutant encoding a putative ATPase was discovered to be compromised in biofilm formation. ATPases are proteins that catalyze ATP in cells and have been suggested to be responsible for stress tolerance, intracellular replication and biofilm formation in bacteria (Frees et al., 2004). The TadA protein is important in biofilm formation in $A$. actinomycetemcomitans and it has been proposed that the ATPase activity of this protein is required to energize the assembly or secretion of Flp pili (Bhattacharjee et al., 2001). However, future studies will be required to determine the functional role of the ATPase gene identified in our screen in biofilm formation.

Although our screen was relatively large, it is likely not saturating. Genes which have been reported to regulate surface associated proteins or biofilm structures of

\section{REFERENCES}

Amarasinghe, J. J., Connell, T. F., Scannapieco, F. A., and Haase, E. M. (2012). Novel iron-regulated and Fur-regulated small regulatory RNAs in Aggregatibacter actinomycetemcomitans. Mol. Oral Microbiol. 27, 327-349. doi: $10.1111 / \mathrm{j} .2041-1014.2012 .00645 . \mathrm{x}$
A. actinomycetemcomitans such as the $d s p B$ (Kaplan et al., 2003) and pgaABCD (Shanmugam et al., 2017) were not picked up in our screen. Analysis of the genome sequence revealed that there are approximately $1.2 \times 10^{5}$ TA sites in A. actinomycetemcomitans genome, therefore, a sample size of at least $1.2 \times 10^{5}$ mutants is needed to achieve a saturated mutagenesis, assuming that each mutation targets a unique site. In addition, this could have also been attributed to different bacterial strains and culture conditions employed. Interestingly, we did not pick up mutation in the same gene twice. This is an indication that Himarl transposon likely occurred randomly in the genome of $A$. actinomycetemcomitans rather than having preference for specific hotspots. Although we have identified several genes associated with biofilm formation of A. actinomycetemcomitans through genome wide screening, these findings needs to be further verified through in-frame gene deletion and complementation studies as transposon insertions could potentially generate polar mutations.

\section{CONCLUSION}

Our data demonstrated that the Himarl transposon is an efficient system to generate random mutants in A. actinomycetemcomitans. This mutagenesis system allows flexibility of carrying out mutagenesis without specific requirement for recipient strains and could be employed to identify novel essential genes for survival and virulence of this periodontal pathogen.

\section{AUTHOR CONTRIBUTIONS}

QD performed the experiments, analyzed the data, and drafted the manuscript. KST conceived the study, analyzed the data, and wrote the manuscript. Both authors have read and approved the final manuscript.

\section{FUNDING}

This study was funded by the grant R221-000-042-133 from the Ministry of Education Singapore.

\section{ACKNOWLEDGMENT}

We thank Yahua Chen (National University of Singapore) for helpful discussion and providing the pUTE664-oriT plasmid.

Barrett, A. R., Kang, Y., Inamasu, K. S., Son, M. S., Vukovich, J. M., and Hoang, T. T. (2008). Genetic tools for allelic replacement in Burkholderia species. Appl. Environ. Microbiol. 74, 4498-4508. doi: 10.1128/AEM. 00531-08

Bhattacharjee, M. K., Kachlany, S. C., Fine, D. H., and Figurski, D. H. (2001). Nonspecific adherence and fibril biogenesis by Actinobacillus 
actinomycetemcomitans: TadA protein is an ATPase. J. Bacteriol. 183, 5927-5936. doi: 10.1128/JB.183.20.5927-5936.2001

Clewell, D. B., and Gawron-Burke, C. (1986). Conjugative transposons and the dissemination of antibiotic resistance in streptococci. Annu. Rev. Microbiol. 40, 635-659. doi: 10.1146/annurev.mi.40.100186.003223

Coros, A. M., Twiss, E., Tavakoli, N. P., and Derbyshire, K. M. (2005). Genetic evidence that GTP is required for transposition of IS903 and Tn552 in Escherichia coli. J. Bacteriol. 187, 4598-4606. doi: 10.1128/JB.187.13.4598-4606. 2005

Dahlén, G., Widar, F., Teanpaisan, R., Papapanou, P., Baelum, V., and Fejerskov, O. (2002). Actinobacillus actinomycetemcomitans in a rural adult population in southern Thailand. Oral Microbiol. Immunol. 17, 137-142. doi: 10.1034/j.1399302X.2002.170301.x

De Kievit, T. R., Parkins, M. D., Gillis, R. J., Srikumar, R., Ceri, H., Poole, K., et al. (2001). Multidrug efflux pumps: expression patterns and contribution to antibiotic resistance in Pseudomonas aeruginosa biofilms. Annu. Rev. Microbiol. 45, 1761-1770. doi: 10.1128/AAC.45.6.1761-1770.2001

Dertli, E., Colquhoun, I. F., Gunning, A. P., Bongaerts, R. J., Le Gall, G., Bonev, B. B., et al. (2013). Structure and biosynthesis of two exopolysaccharides produced by Lactobacillus johnsonii FI9785. J. Biol. Chem. 288, 31938-31951. doi: 10.1074/jbc.M113.507418

Ding, Q., Quah, S. Y., and Tan, K. S. (2016). Secreted adenosine triphosphate from Aggregatibacter actinomycetemcomitans triggers chemokine response. Mol. Oral Microbiol. 31, 423-434. doi: 10.1111/omi.12143

Fine, D. H., Furgang, D., and Barnett, M. L. (2001). Comparative antimicrobial activities of antiseptic mouthrinses against isogenic planktonic and biofilm forms of Actinobacillus actinomycetemcomitans. J. Clin. Periodontol. 28, 697-700. doi: 10.1034/j.1600-051x.2001.028007697.x

Flemming, H. C., Neu, T. R., and Wozniak, D. J. (2007). The EPS matrix: the "house of biofilm cells". J. Bacteriol. 189, 7945-7947. doi: 10.1128/JB.00858-07

Frees, D., Chastanet, A., Qazi, S., Sørensen, K., Hill, P., Msadek, T., et al. (2004). Clp ATPases are required for stress tolerance, intracellular replication and biofilm formation in Staphylococcus aureus. Mol. Microbiol. 54, 1445-1462. doi: 10.1111/j.1365-2958.2004.04368.x

Geesey, G. G., Wigglesworth-Cooksey, B., and Cooksey, K. E. (2000). Influence of calcium and other cations on surface adhesion of bacteria and diatoms: a review. Biofouling 15, 195-205. doi: 10.1080/089270100093 86310

Goryshin, I., Miller, J., Kil, Y., Lanzov, V., and Reznikoff, W. (1998). Tn5/IS50 target recognition. Proc. Natl. Acad. Sci. U.S.A. 95, 10716-10721. doi: 10.1073/pnas.95. 18.10716

Halling, S. M., and Kleckner, N. (1982). A symmetrical six-base-pair target site sequence determines Tn10 insertion specificity. Cell 28, 155-163. doi: 10.1016/ 0092-8674(82)90385-3

Haubek, D., Ennibi, O., Poulsen, K., Vaeth, M., Poulsen, S., and Kilian, M. (2008). Risk of aggressive periodontitis in adolescent carriers of the JP2 clone of Aggregatibacter (Actinobacillus) actinomycetemcomitans in Morocco: a prospective longitudinal cohort study. Lancet 371, 237-242. doi: 10.1016/ S0140-6736(08)60135-X

Inoue, T., Tanimoto, I., Ohta, H., Kato, K., Murayama, Y., and Fukui, K. (1998). Molecular characterization of low-molecular-weight component protein, Flp, in Actinobacillus actinomycetemcomitans fimbriae. Microbiol. Immunol. 42, 253-258. doi: 10.1111/j.1348-0421.1998.tb02280.x

Isaza, M. P., Duncan, M. S., Kaplan, J. B., and Kachlany, S. C. (2008). Screen for leukotoxin mutants in Aggregatibacter actinomycetemcomitans: genes of the phosphotransferase system are required for leukotoxin biosynthesis. Infect. Immun. 76, 3561-3568. doi: 10.1128/IAI. 01687-07

Kachlany, S. C. (2010). Aggregatibacter actinomycetemcomitans leukotoxin: from threat to therapy. J. Dent. Res. 89, 561-570. doi: 10.1177/0022034510363682

Kachlany, S. C., Fine, D. H., and Figurski, D. H. (2000a). Secretion of RTX leukotoxin by Actinobacillus actinomycetemcomitans. Infect. Immun. 68, 6094-6100.

Kachlany, S. C., Planet, P. F., Bhattacharjee, M. K., Kollia, E., Desalle, R., Fine, D. H., et al. (2000b). Nonspecific adherence by Actinobacillus actinomycetemcomitans requires genes widespread in bacteria and archaea. J. Bacteriol. 182, 6169-6176.
Kaplan, J. B., Ragunath, C., Ramasubbu, N., and Fine, D. H. (2003). Detachment of Actinobacillus actinomycetemcomitans biofilm cells by an endogenous betahexosaminidase activity. J. Bacteriol. 185, 4693-4698. doi: 10.1128/JB.185.16. 4693-4698.2003

Klein, B. A., Tenorio, E. L., Lazinski, D. W., Camilli, A., Duncan, M. J., and $\mathrm{Hu}, \mathrm{L}$. T. (2012). Identification of essential genes of the periodontal pathogen Porphyromonas gingivalis. BMC Genomics 13:578. doi: 10.1186/1471-216413-578

Kolodrubetz, D., and Kraig, E. (1994). Transposon Tn5 mutagenesis of Actinobacillus actinomycetemcomitans via conjugation. Oral Microbiol. Immunol. 9, 290-296. doi: 10.1111/j.1399-302X.1994.tb00073.x

Kvist, M., Hancock, V., and Klemm, P. (2008). Inactivation of efflux pumps abolishes bacterial biofilm formation. Appl. Environ. Microbiol. 74, 7376-7382. doi: 10.1128/AEM.01310-08

Lampe, D. J., Grant, T. E., and Robertson, H. M. (1998). Factors affecting transposition of the Himarl mariner transposon in vitro. Genetics 149, 179-187.

Leibig, M., Liebeke, M., Mader, D., Lalk, M., Peschel, A., and Götz, F. (2011). Pyruvate formate lyase acts as a formate supplier for metabolic processes during anaerobiosis in Staphylococcus aureus. J. Bacteriol. 193, 952-962. doi: 10.1128/ JB.01161-10

Levander, F., and Rådström, P. (2001). Requirement for phosphoglucomutase in exopolysaccharide biosynthesis in glucose- and lactose-utilizing Streptococcus thermophilus. Appl. Environ. Microbiol. 67, 2734-2738. doi: 10.1128/AEM.67.6. 2734-2738.2001

Martin, B. F., Derby, B. M., Budzilovich, G. N., and Ransohoff, J. (1967). Brain abscess due to Actinobacillus actinomycetemcomitans. Neurology 17, 833-837. doi: 10.1212/WNL.17.9.833

Meyer, D., and Fives-Taylor, P. (1998). Oral pathogens: from dental plaque to cardiac disease. Curr. Opin. Microbiol. 1, 88-95. doi: 10.1016/S1369-5274(98) 80147-1

Mullany, P., Williams, R., Langridge, G. C., Turner, D. J., Whalan, R., Clayton, C., et al. (2012). Behavior and target site selection of conjugative transposon Tn916 in two different strains of toxigenic Clostridium difficile. Appl. Environ. Microbiol. 78, 2147-2153. doi: 10.1128/AEM. 06193-11

Nilsson, M., Christiansen, N., Hoiby, N., Twetman, S., Givskov, M., and Tolker-Nielsen, T. (2014). A mariner transposon vector adapted for mutagenesis in oral streptococci. Microbiologyopen 3, 333-340. doi: 10.1002/ mbo3.171

Nunes, A. C., Longo, P. L., and Mayer, M. P. (2016). Influence of Aae autotransporter protein on adhesion and biofilm formation by Aggregatibacter actinomycetemcomitans. Braz. Dent. J. 27, 255-260. doi: 10.1590/01036440201600260

Perez, B. A., Planet, P. J., Kachlany, S. C., Tomich, M., Fine, D. H., and Figurski, D. H. (2006). Genetic analysis of the requirement for $f l p-2$, $\operatorname{tad} V$, and $r c p B$ in Actinobacillus actinomycetemcomitans biofilm formation. J. Bacteriol. 188, 6361-6375. doi: 10.1128/JB.00496-06

Planet, P. J., Kachlany, S. C., Fine, D. H., Desalle, R., and Figurski, D. H. (2003). The widespread colonization island of Actinobacillus actinomycetemcomitans. Nat. Genet. 34, 193-198. doi: 10.1038/ng1154

Rhodes, E. R., Menke, S. F., Shoemaker, C., Tomaras, A. P., Mcgillivary, G., and Actis, L. A. (2007). Iron acquisition in the dental pathogen Actinobacillus actinomycetemcomitans: what does it use as a source and how does it get this essential metal? Biometals 20, 365-377.

Sambrook, J., Fritsch, E., and Maniatis, T. (1989). Molecular Cloning: A Laboratory Manual, 2nd Edn. Cold Spring Harbor, NY: Cold Spring Harbor Laboratory Press.

Shanmugam, M., Oyeniyi, A. O., Parthiban, C., Gujjarlapudi, S. K., Pier, G. B., and Ramasubbu, N. (2017). Role of de-N-acetylase PgaB from Aggregatibacter actinomycetemcomitans in exopolysaccharide export in biofilm mode of growth. Mol. Oral Microbiol. doi: 10.1111/omi.12188 [Epub ahead of print].

Shenker, B. J., Besack, D. F., Mckay, T., Pankoski, L., Zekavat, A., and Demuth, D. R. (2004). Actinobacillus actinomycetemcomitans cytolethal distending toxin (Cdt): evidence that the holotoxin is composed of three subunits: CdtA, CdtB, and CdtC. J. Immunol. 172, 410-417. doi: 10.4049/jimmunol.172. 1.410 
Slots, J., Reynolds, H., and Genco, R. (1980). Actinobacillus actinomycetemcomitans in human periodontal disease: a cross-sectional microbiological investigation. Infect. Immun. 29, 1013-1020.

Teixeira, R. E., Mendes, E. N., Roque de Carvalho, M. A., Nicoli, J. R., Farias Lde, M., and Magalhaes, P. P. (2006). Actinobacillus actinomycetemcomitans serotype-specific genotypes and periodontal status in Brazilian subjects. Can. J. Microbiol. 52, 182-188. doi: 10.1139/W05-121

Thomson, V. J., Bhattacharjee, M. K., Fine, D. H., Derbyshire, K. M., and Figurski, D. H. (1999). Direct selection of IS903 transposon insertions by use of a broadhost-range vector: isolation of catalase-deficient mutants of Actinobacillus actinomycetemcomitans. J. Bacteriol. 181, 7298-7307.

Thrower, Y., Pinney, R., and Wilson, M. (1997). Susceptibilities of Actinobacillus actinomycetemcomitans biofilms to oral antiseptics. J. Med. Microbiol. 46, 425-429. doi: 10.1099/00222615-46-5-425

van Winkelhoff, A. J., and Slots, J. (1999). Actinobacillus actinomycetemcomitans and Porphyromonas gingivalis in nonoral infections. Periodontol. 2000 20, 122-135. doi: 10.1111/j.1600-0757.1999.tb00160.x

Withers, T. R., Yin, Y., and Yu, H. D. (2014). Identification of novel genes associated with alginate production in Pseudomonas aeruginosa using minihimar1 mariner transposon-mediated mutagenesis. J. Vis. Exp. 85:e51346. doi: $10.3791 / 51346$
Yang, H., Huang, Y., Chan, Y., and Chou, M. (2005). Relationship of Actinobacillus actinomycetemcomitans serotypes to periodontal condition: prevalence and proportions in subgingival plaque. Eur. J. Oral Sci. 113, 28-33. doi: 10.1111/j. 1600-0722.2004.00192.x

Zambon, J. J. (1985). Actinobacillus actinomycetemcomitans in human periodontal disease. J. Clin. Periodontol. 12, 1-20. doi: 10.1111/j.1600-051X.1985. tb01348.x

Zambon, J. J., Christersson, L. A., and Jorgen, S. (1983). Actinobacillus actinomycetemcomitans in human periodontal disease. J. Periodontol. 54, 707-711. doi: 10.1902/jop.1983.54.12.707

Conflict of Interest Statement: The authors declare that the research was conducted in the absence of any commercial or financial relationships that could be construed as a potential conflict of interest.

Copyright $\odot 2017$ Ding and Tan. This is an open-access article distributed under the terms of the Creative Commons Attribution License (CC BY). The use, distribution or reproduction in other forums is permitted, provided the original author(s) or licensor are credited and that the original publication in this journal is cited, in accordance with accepted academic practice. No use, distribution or reproduction is permitted which does not comply with these terms. 